\title{
SYNTHESIS OF $\mathrm{WO}_{3}$ NANORODS AND THEIR PHOTOCATALYTIC DEGRADATION OF ORGANIC CONTAMINANTS
}

\author{
T. Jeyapaul ${ }^{1}$, K. Prakash ${ }^{2}$, S. Harikengaram ${ }^{3}$, A. Chellamani ${ }^{4}$ \\ and V. Selvam, ${ }^{1, *}$ \\ ${ }^{1}$ Department of Chemistry, The MDT Hindu College, Affiliated to Manonmaniam Sundaranar \\ University Tirunelveli-627010, Tamil Nadu, India \\ ${ }^{2}$ Department of Chemistry, VHNSN College, Virudhunagar-626001, Tamil Nadu, India \\ ${ }^{3}$ Department of Chemistry, PMT College, Tirunelveli, Tamil Nadu, India \\ ${ }^{4}$ Department of Chemistry, Manonmaniam Sundaranar University, \\ Tirunelveli, Tamil Nadu, India \\ *E-mail: selvam.che@gmail.com
}

\begin{abstract}
In this present investigation, we report a novel tungsten trioxide $\left(\mathrm{WO}_{3}\right)$ nanorods were successfully synthesized by the simple hydrothermal environment. The as-synthesized rod-like $\mathrm{WO}_{3}$ were characterized by various spectroscopic and analytical techniques such as X-ray diffraction (XRD) UV-vis spectroscopy analysis (UV-DRS). The structural morphology and their elements were confirmed by scanning electron microscopy (SEM) and energy-dispersive Xray spectroscopy (EDX). It was found that the rod-like structure of $\mathrm{WO}_{3}$ was successfully confirmed by transmission electron microscopy (TEM). The synthesized $\mathrm{WO}_{3}$ exhibits an excellent photocatalytic activity which may be attributed to the improved charge separation and complete degradation of RhB dye solution within 70 min. The photocatalyst efficiency was further tested towards the effect of dye concentration and effect of different catalyst weight. The involvement of. $\mathrm{OH}$ in the photocatalytic reaction was evidenced using radical quenching experiment with employing different scavengers. A possible degradation mechanism was proposed for the semiconductors and possible reasons for the enhancement of visible-light photocatalytic efficiency were discussed. This study could provide a new approach to construct a novel photocatalysts and a promising candidate catalyst for poisonous wastewater treatment in the near future.
\end{abstract}

Keywords: $\mathrm{WO}_{3}$, hydrothermal, $\mathrm{RhB}$ dye, photocatalyst, the mechanism

(C) RASĀYAN. All rights reserved

\section{INTRODUCTION}

Driven by increasing environmental pollution and the growing threat of the current energy crisis, the search for cost-effective, sustainable and green energy sources to meet global energy demands has attracted considerable research attention ${ }^{1}$. Utilization of solar energy to complete degradation of organic pollutants using highly effective photocatalyst has long been considered the ultimate solution because semiconductor-based photocatalysis is an ambient temperature and green chemical process ${ }^{2}$. In the past few decades, metal oxides ${ }^{3-5}$ metal sulfides ${ }^{6}$ and bismuth-based ${ }^{7}$ and Ag-based compounds were extensively developed for photocatalytic applications ${ }^{8}$. Among semiconductors, metal oxides were one type of attractive and promising material owing to their abundance, low cost, nontoxic, and relatively high chemical stability ${ }^{9}$.Among them, $\mathrm{WO}_{3}$ also showed excellent optical, gas-sensing properties and chemical stability, which was wide, used in sensors, solar cells and lithium-ion batteries. ${ }^{10-15}$ However, it was difficult to respond to visible light because of its wide band gap, so the studies on the photocatalytic behavior of $\mathrm{WO}_{3}$ under visible light irradiation had rarely been reported. Therefore, development of visible light active $\mathrm{WO}_{3}$ is an important concern to the researchers.

Rasayan J. Chem., 11(4), 1405-1414(2018)

http://dx.doi.org/10.31788/RJC.2018.1143076

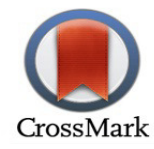


Recent years, many efforts have been devoted to synthesize $1 \mathrm{D} \mathrm{WO}_{3}$ nanostructures via various routes such as the sol-gel process, spray pyrolysis, pulsed laser ablation, chemical vapor deposition and thermal evaporation. ${ }^{16-18}$ Nevertheless, many of those synthetic methods have some limitations such as need high vacuum and reaction temperature or complicated reaction processing steps. High temperatures are usually responsible for undesired particle growth and may decrease the surface areas and increase particle sizes.

Herein we report a novel simple hydrothermal route for the synthesis of a visible light active $\mathrm{WO}_{3}$ photocatalyst for the photodegradation of $\mathrm{RhB}$ dye solution for the first time from the best of our authors. The prepared $\mathrm{WO}_{3}$ were characterized by XRD, TEM, SEM, and UV and discussed in detail. The prepared $\mathrm{WO}_{3}$ photocatalyst exhibited improved photocatalytic performance towards the degradation of $\mathrm{RhB}$. The photocatalyst efficiency was further tested towards the dye concentration, catalyst dosage, and different scavengers of the dye solution.

\section{Chemicals}

\section{EXPERIMENTAL}

Sodium tungstate, Sodium Chloride, Hydrochloric acid, Rhodamine B were purchased from SigmaAldrich and used as such without any further purification.

\section{Synthesis of $\mathrm{WO}_{3}$ Nanorods}

The $\mathrm{WO}_{3}$ nanorod was prepared by the simple hydrothermal environment. In a typical synthesis, $1.527 \mathrm{~g}$ of $\mathrm{NaWO}_{4} .2 \mathrm{H}_{2} \mathrm{O}$ and $0.351 \mathrm{~g}$ of $\mathrm{NaCl}$ were dissolved into $20 \mathrm{~mL}$ of deionized water and then $3 \mathrm{~mL}$ of 2 $\mathrm{M} \mathrm{HCl}$ solution was added and vigorous stirring for 30 minutes. Subsequently, the resulting light sky blue solution was transferred into a Teflon-lined sealed stainless steel autoclave at $180{ }^{\circ} \mathrm{C}$ for $48 \mathrm{~h}$. Then, the precipitate was washed with copious amount of DI water and absolute ethanol and then dried at $60{ }^{\circ} \mathrm{C}$ for $12 \mathrm{~h}$.

\section{Photocatalytic Activity of $\mathrm{WO}_{3}$ Nanorods}

X-Ray Diffraction measurements were carried out using a Bruker D8 diffractometer with $\mathrm{Cu}-\mathrm{Ka}$ radiation $(1=1.540598 \AA)$ in the angular range of $10-80^{\circ}(2 \theta)$ with an accelerating voltage of $40 \mathrm{kV}$ and a current of $20 \mathrm{~mA}$. The morphology, particle size and chemical composition of the product were examined by scanning electron microscopy (SEM VEGA3 TESCAN) and transmission electron microscopy(TEM, JEM-2100, and JEOL, JAPAN). PL spectra were measured using room temperature photoluminescence with a $325 \mathrm{~nm}$ He-Cd laser excitation wavelength (Shimadzu RF-5301). Shimadzu diffuse reflectance UV-Vis-1800 spectrometer was used to analyze the nanomaterials (Scheme-1).

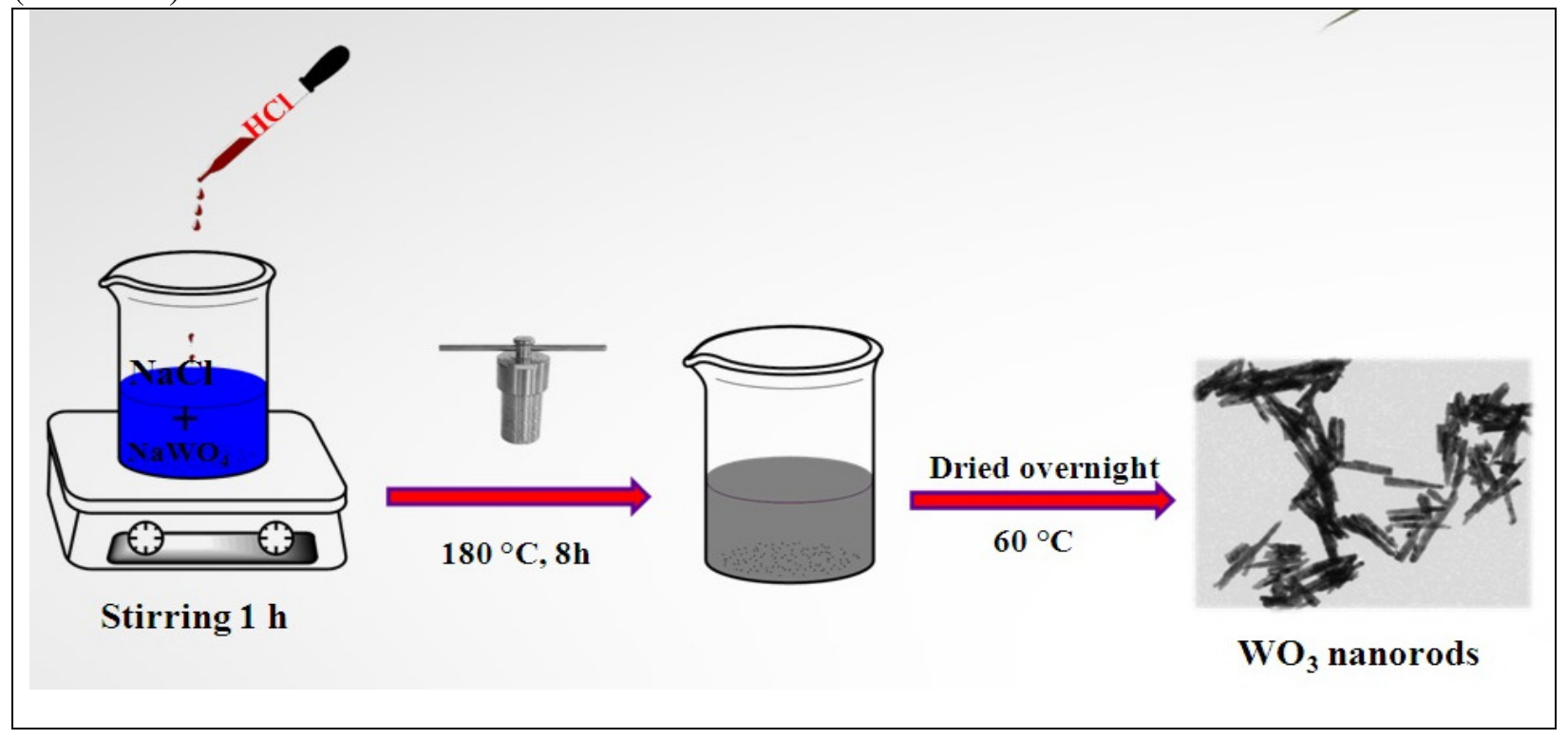

Scheme-1: Schematic Diagram of Synthesized of $\mathrm{WO}_{3}$ Nanorods 


\section{Evaluation of Photocatalytic Activity}

The photocatalytic activity of $\mathrm{WO}_{3}$ nanorods was evaluated towards the degradation of $\mathrm{RhB}$ dye solution under visible light irradiation $(>450 \mathrm{~nm})$. A Heber photoreactor was used to the photodegradation reaction. (A $300 \mathrm{~W}$ tungsten incandescent lamp was used as visible light source). $50 \mathrm{mg}$ of $\mathrm{WO}_{3}$ photocatalyst was added to $75 \mathrm{~mL}$ of the $\mathrm{RhB}$ dye solution in $150 \mathrm{~mL}$ reaction vessel. At given time intervals, $5 \mathrm{~mL}$ of aliquots were collected. The degraded solutions were analyzed using the absorption peaks at $664 \mathrm{~nm}$. Prior to irradiation, the suspensions were magnetically stirred in the dark condition for $1 \mathrm{~h}$ to ensure the equilibrium of the working solution.

\section{Structural Analysis}

\section{RESULTS AND DISCUSSION}

The phase and crystalline nature of the as-synthesized $\mathrm{WO}_{3}$ nanorods were investigated by XRD and are shown in Fig.-1. The $\mathrm{WO}_{3}$ Monoclinic phase was well matched with the standard JCPDS Card No 83$0950^{19}$. The characteristic $2 \theta$ regions of $16.86,24.34,25.96,33.58,34.13,35.38,39.21,42.95,46.01$ and 49.89 were corresponds to (110), (200), (012), (202), (220), (122), (112), (032), (312) and (400) planes indicating the crystalline nature of $\mathrm{WO}_{3}$. Especially, the XRD pattern preferred (012) orientation which has the higher intensity suggested that the $\mathrm{WO}_{3}$ nanorods grown along the (012) plane. Any other phases are not detected in the above results indicated the high purity of the as-synthesized $\mathrm{WO}_{3}$ nanorods.

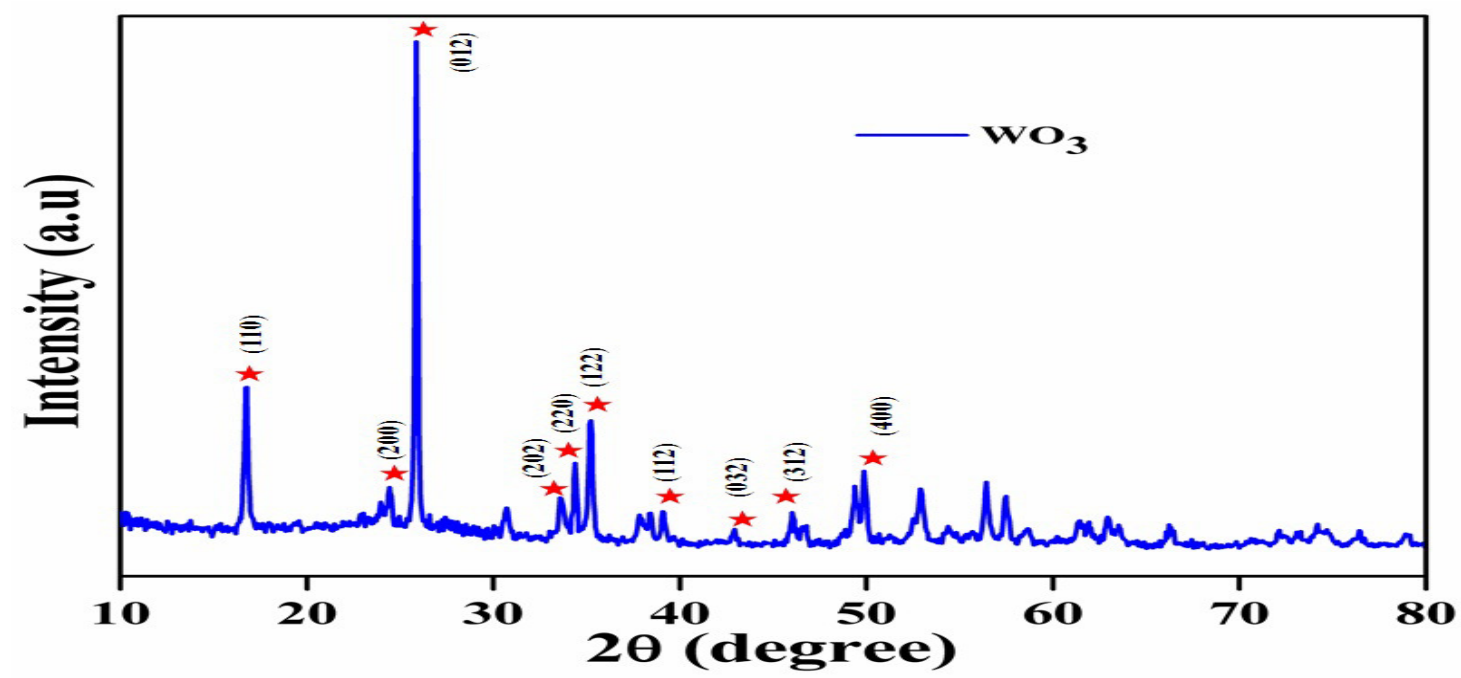

Fig.-1: XRD Patterns of Synthesized $\mathrm{WO}_{3}$ Nanorods

The average crystallite size D, was calculated using the well known Debye Scherrer's equation ${ }^{20}$, as:

$$
D=\frac{k \lambda}{\beta \operatorname{Cos} \theta}
$$

Where, $D$ is the crystalline size, $\lambda$ is the wavelength of the $X$-ray, $\beta$ is the (Full Width at Half Maximum) FWHM of the diffraction peak, $\theta$ is the diffraction angle and $\mathrm{k}$ is the Scherrer's constant of the order of unity. The average crystalline sizes of the synthesized $\mathrm{WO}_{3}$ nanorods were around $36.26 \mathrm{~nm}$.

\section{Morphological Analysis}

The morphology and microstructure of the as-synthesized $\mathrm{WO}_{3}$ were investigated by SEM and TEM as shown in Fig.-2. The SEM micrographs of synthesized $\mathrm{WO}_{3}$ were seemed to be rod-like structures with the particle size about $200 \mathrm{~nm}$ which is shown in Fig.-2a. Interestingly, (Fig.-2b) the SEM micrographs synthesized $\mathrm{WO}_{3}$ clearly showed that a numerous rod-like structures. Fig 2(c-d) shows TEM images of $\mathrm{WO}_{3}$ nanorods with the diameter range about 20-30 nm with the calculated value is approximately $35 \mathrm{~nm}$. This result is in good agreement with the XRD pattern. 


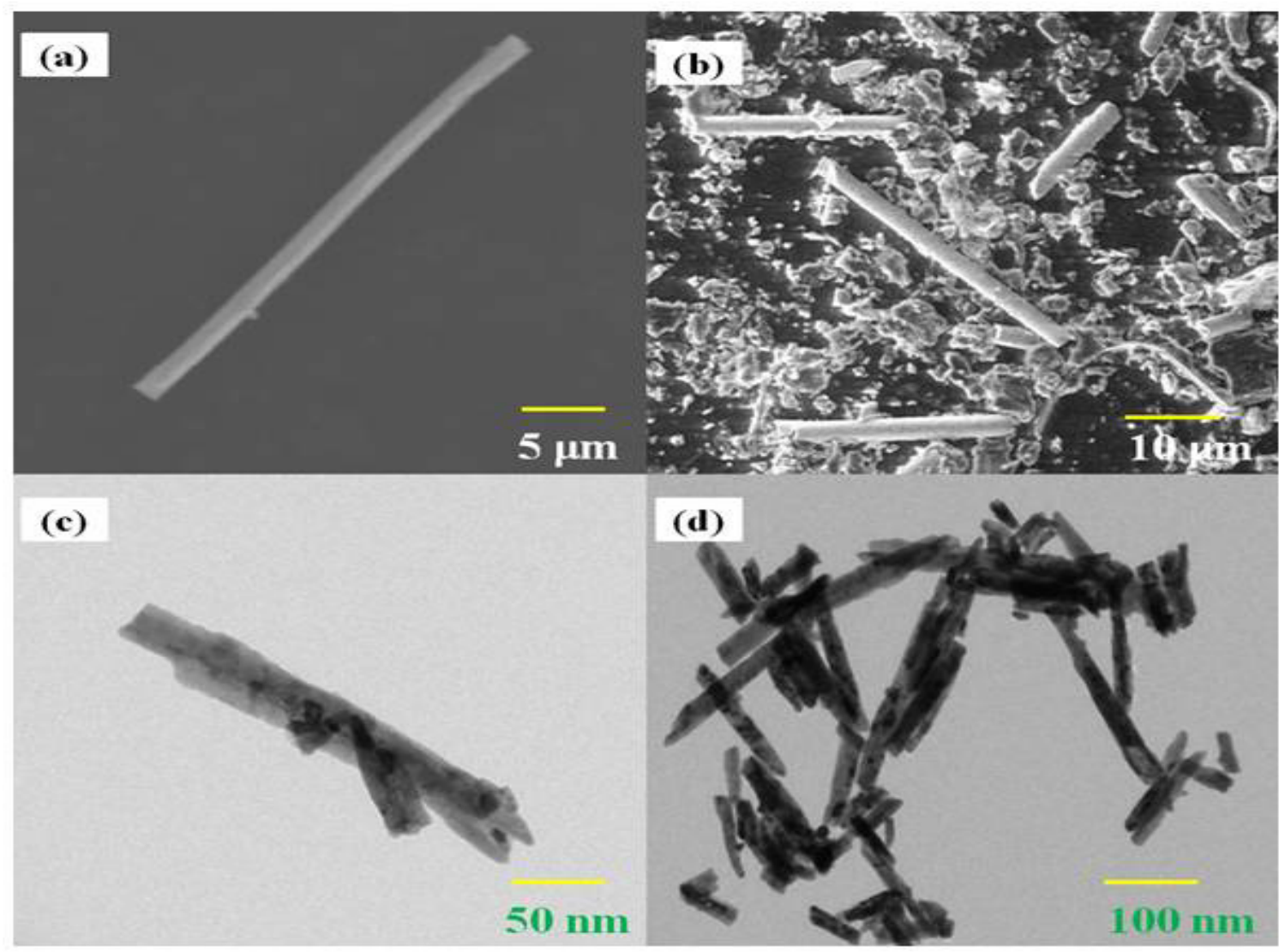

Fig.-2: (a-b) SEM Micrographs of Synthesized $\mathrm{WO}_{3}$, (c-d) TEM Images of Synthesized $\mathrm{WO}_{3}$ Nanorods

\section{EDAX and Elemental Mapping Analysis}

The composition of elements present in the as-synthesized $\mathrm{WO}_{3}$ nanorods was analyzed by energy dispersive X-ray (EDX) analysis which is shown in Fig.-3. The EDX results clearly indicated that the $\mathrm{WO}_{3}$ nanorod contains only $\mathrm{W}$ and $\mathrm{O}$ with the weight percentage of $26.52 \%$ and $73.48 \%$, respectively. No other elements were present in the $\mathrm{WO}_{3}$ nanorods which suggested the purity of the synthesized photocatalyst. In addition, Fig. -4 shows the composition of the elements present in the $\mathrm{WO}_{3}$ nanorods were solid evidenced by elemental mapping analysis. These results well confirmed the presence of tungsten and oxygen is uniformly distributed in the $\mathrm{WO}_{3}$ nanorods.

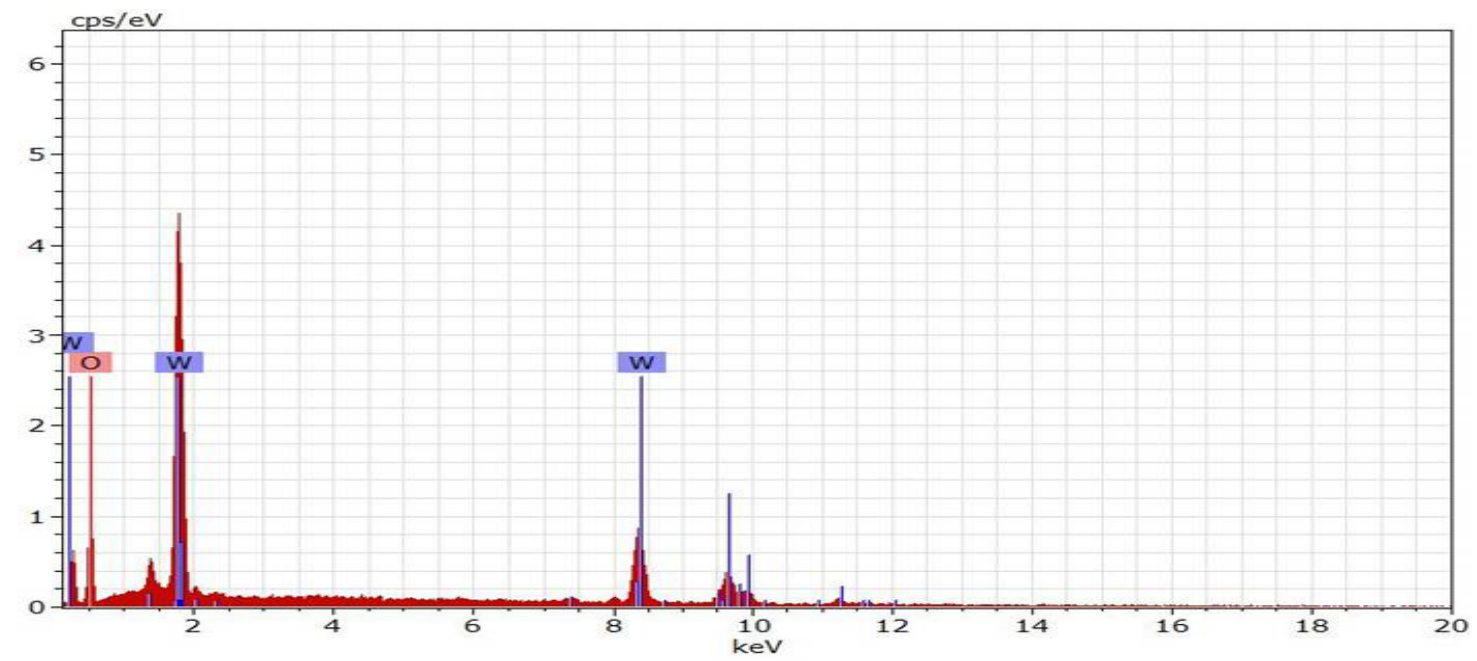

Fig.-3: EDX Spectrum of the Synthesized $\mathrm{WO}_{3}$ Nanorods 


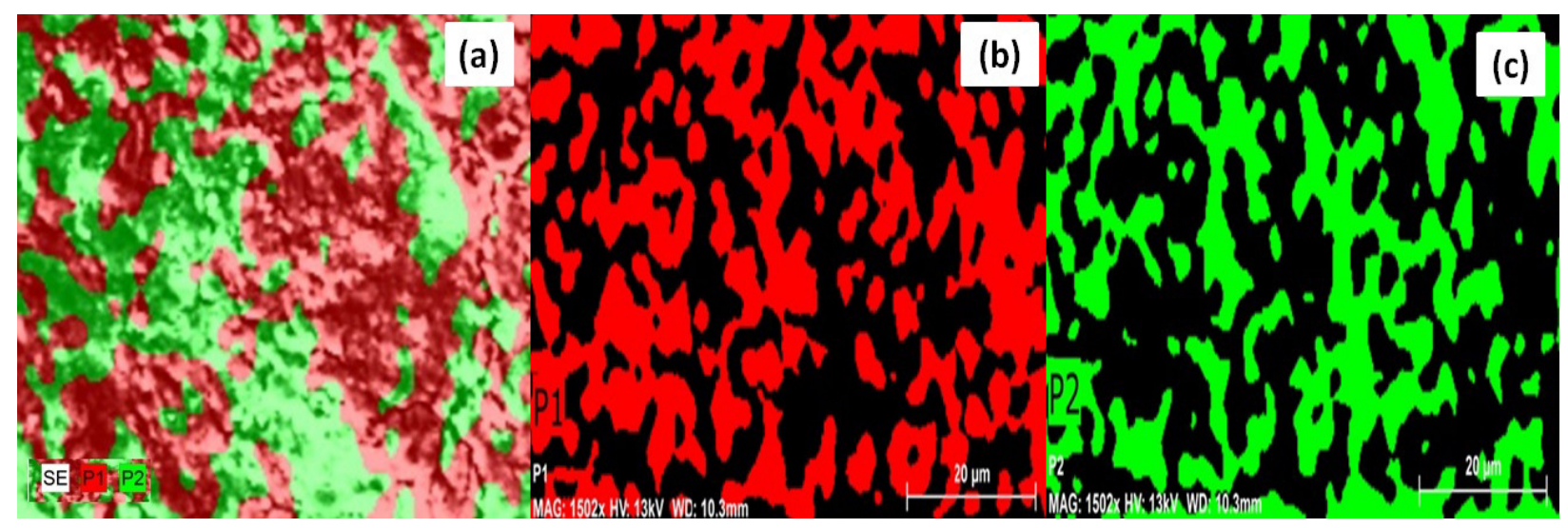

Fig.-4: (a) Elemental Mapping Images of Synthesized $\mathrm{WO}_{3}$, (b) Tungsten, (c) Oxygen

\section{Optical Properties}

The optical absorption properties of the synthesized $\mathrm{WO}_{3}$ are a vital parameter for the selection of the right kind of light needed for the degradation of the organic dye solution. It displayed that, $\mathrm{WO}_{3}$ nanorods Sharpe absorption steep edges at about $375 \mathrm{~nm}$ in the range of visible light Fig.-5a. The band gap energy value was calculated by using Tauc's plots relationship which relates the absorption coefficient and incident photon energy of $\mathrm{WO}_{3}$. The equation is given below:

$$
(\alpha h v)^{2}=A\left(h v-E_{g}\right)^{n}
$$

Therefore, the band gap for $\mathrm{WO}_{3}$ nanorods, a plot of $(\alpha \mathrm{hv})^{2}$ is plotted against the photon energy (hv) was calculated and displayed in Fig.-5b. The direct band gap energy was estimated by extrapolating the line segment of the plot $(\alpha h v)^{2}$ vs ho to zero absorption co-efficient value. The calculated band gap energy of the $\mathrm{WO}_{3}$ nanorods was extrapolated lines and the values about $2.7 \mathrm{eV}$ and hence the $\mathrm{WO}_{3}$ nanorods can be used as an excellent photocatalyst for the degradation of dyes under visible light irradiation ${ }^{21}$.
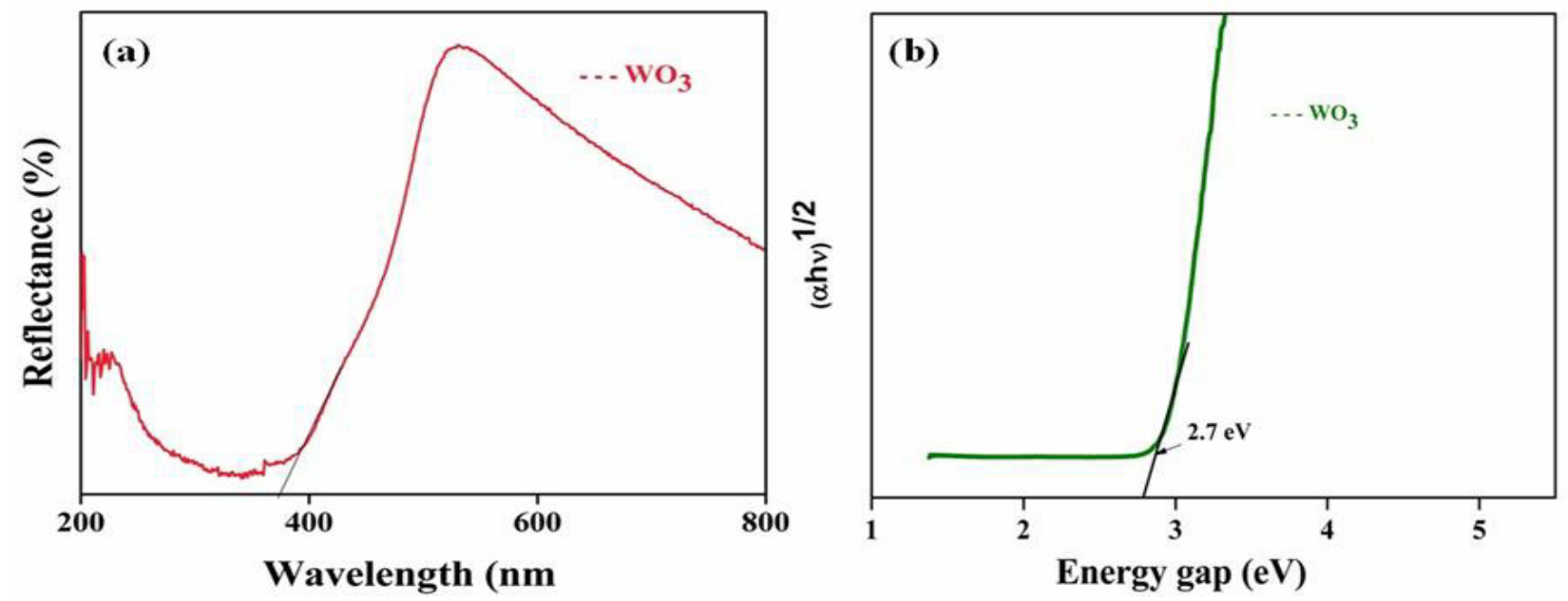

Fig.-5: (a) UV-Vis Spectra (DRS Mode) of $\mathrm{WO}_{3}$ Nanorods and (b) Tauc's Plot of $\mathrm{WO}_{3}$ Nanorods

The PL spectrum correlated with movement of electron transfer efficiency, in order that it can reflect photogenerated electron-hole pair separation capacity of the charge carriers. The strong PL intensity indicates the faster recombination rate of the photoexcited electron-hole combine and a lower PL intensity expresses a depressed recombination rate and hence a longer lifetime of the charge carriers. The excitation wavelength for PL spectra of $\mathrm{WO}_{3}$ was set at $375 \mathrm{~nm}$ which is shown in Fig.-6. The main emission peak is centered at about $450 \mathrm{~nm}$ for pristine $\mathrm{WO}_{3}$ indicating that the electron- 
RASĀYAN J. Chem.

Vol. 11 | No. 4 |1405 - 1414| October - December | 2018

hole pair separation rapidly ${ }^{22,23}$. The $\mathrm{WO}_{3}$ nanorods showed improved charge transport characteristic which may facilitate charge transfer.

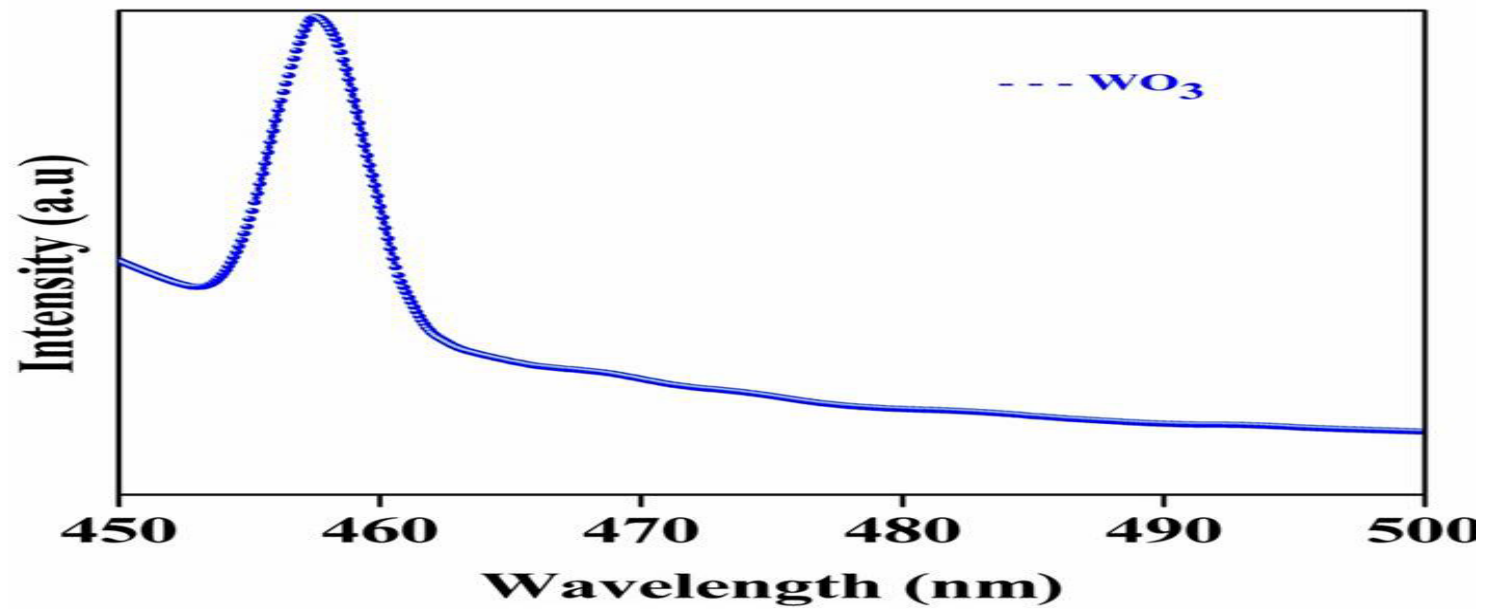

Fig.-6: Photoluminescence Spectrum of Synthesized $\mathrm{WO}_{3}$ Nanorods

\section{Photocatalytic Activity}

The photocatalytic activity of the synthesized $\mathrm{WO}_{3}$ nanorods was evaluated on photocatalytic degradation of Rhodamine $\mathrm{B}(\mathrm{RhB})$ dye solution under visible light irradiation shown in Fig.-7. The photo degradation of the dye was monitored by the absorption peak at $556 \mathrm{~nm}$ which are shown in Fig.-7. The dye was completely degraded within $70 \mathrm{~min}$ and the degradation percentage has been reached almost $95 \%$. These results prompted that $\mathrm{WO}_{3}$ nanorods can act as an excellent photocatalyst for the degradation of the dye solution.
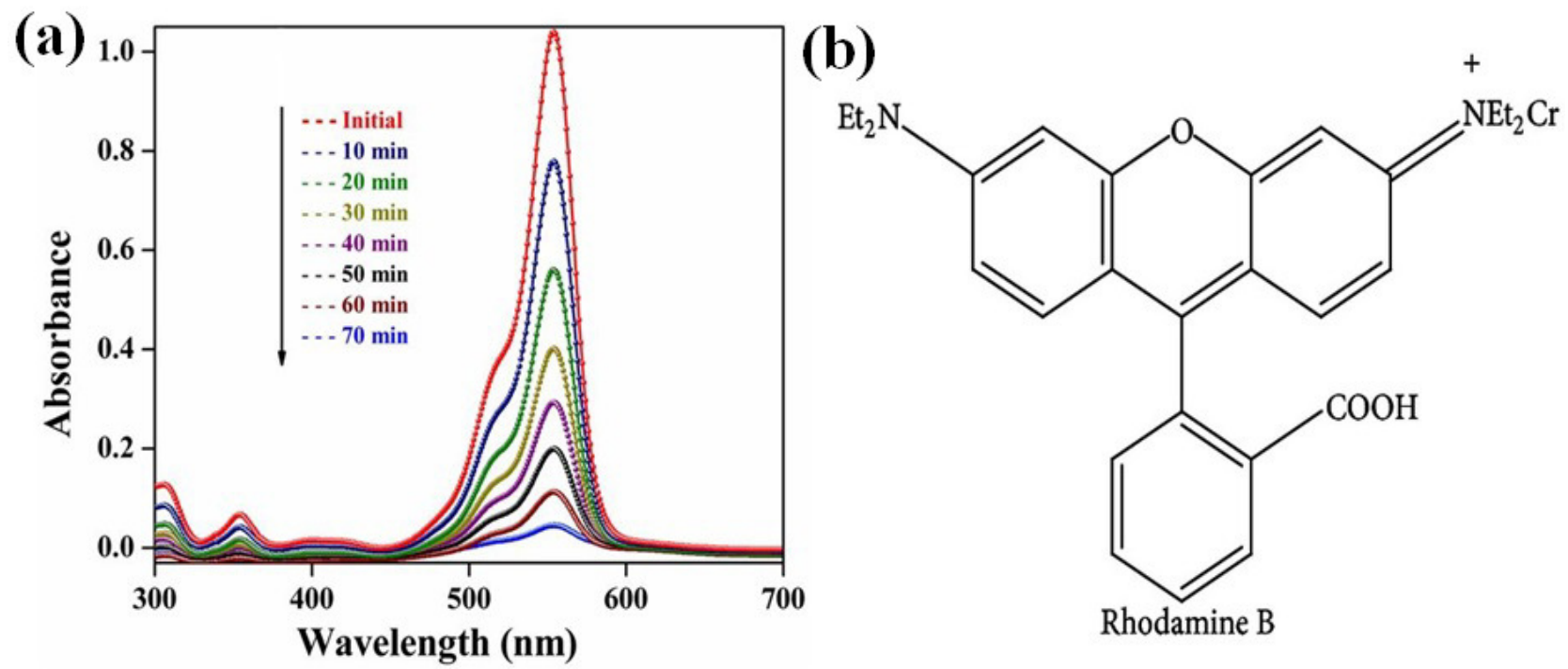

Fig.-7: Absorption Spectra of a Solution of $\mathrm{RhB}$ in the Presence of $\mathrm{WO}_{3}$ Photocatalyst (50mg) under Exposure to

\section{Effect of Dyes Concentration} Visible Light (b) Structure of RhB Dye

The effect of concentration of $\mathrm{RhB}$ dye on the photocatalytic degradation was studied by different the dye concentration from $5 \mathrm{ppm}$ to $20 \mathrm{ppm}$ was shown in Fig.-8. The photocatalytic rate was high when the concentration of dye is low and vice versa while increasing the concentration of dye, more molecules of dye are accessible for the excitation and degradation. When the concentration of dye increases from 10 to $20 \mathrm{ppm}$, the rate of photodegradation decreased due to the reduced interaction of photons with the active site and thereby reduces the light intensity reached on the photocatalyst surface. ${ }^{24}$ 
RASĀYAN $J$. Chem.

Vol. 11 | No. 4 |1405 - 1414| October - December | 2018

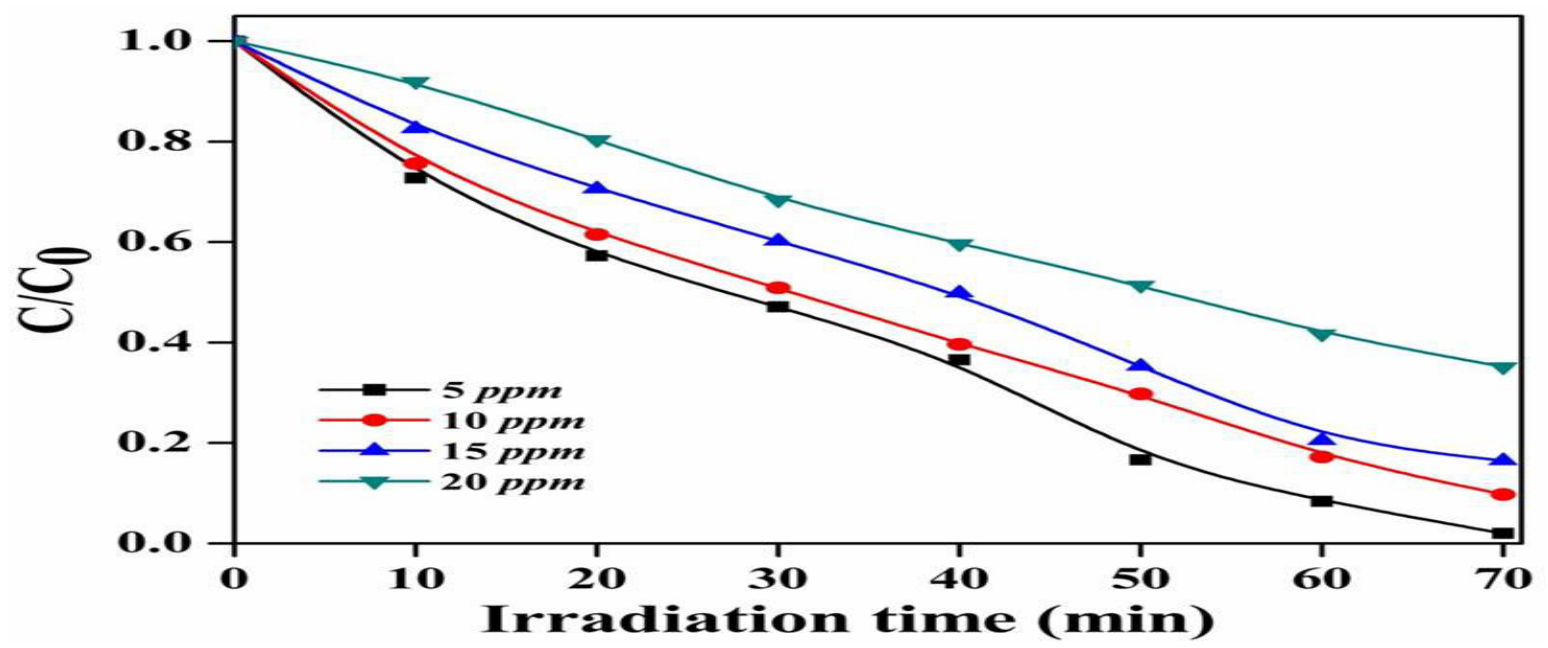

Fig.-8: Photodegradation of RhB with Different Dye Concentration in the Presence of $\mathrm{WO}_{3}$ Photocatalyst

\section{Effect of Catalyst}

To investigate the effect of the catalyst loading on the degradation of $\mathrm{RhB}$ the amount of $\mathrm{WO}_{3}$ varied from 10 to $75 \mathrm{mg}$. The photodegradation rate of the dye solution at a different amount of $\mathrm{WO}_{3}$ shown in Fig.-9. The photodegradation rate was high when the amount of $\mathrm{WO}_{3}$ was $50 \mathrm{mg}$. The catalyst with $5 \mathrm{mg}$ of loading produces the highest photodegradation rate of dye. Amount of $\mathrm{WO}_{3}$ below $50 \mathrm{mg}$, produces fewer holes with unit time and can produce lesser high active sites on the catalyst surface, and hence the photodegradation rate is lower. Whereas the amount of $\mathrm{WO}_{3}$ above $50 \mathrm{mg}$, the solution becomes very turbid which prevent light passage and in turn increase the light scattering. Thus, the $50 \mathrm{mg}$ of the photocatalyst is the optimum amount of photocatalytic degradation. ${ }^{25}$

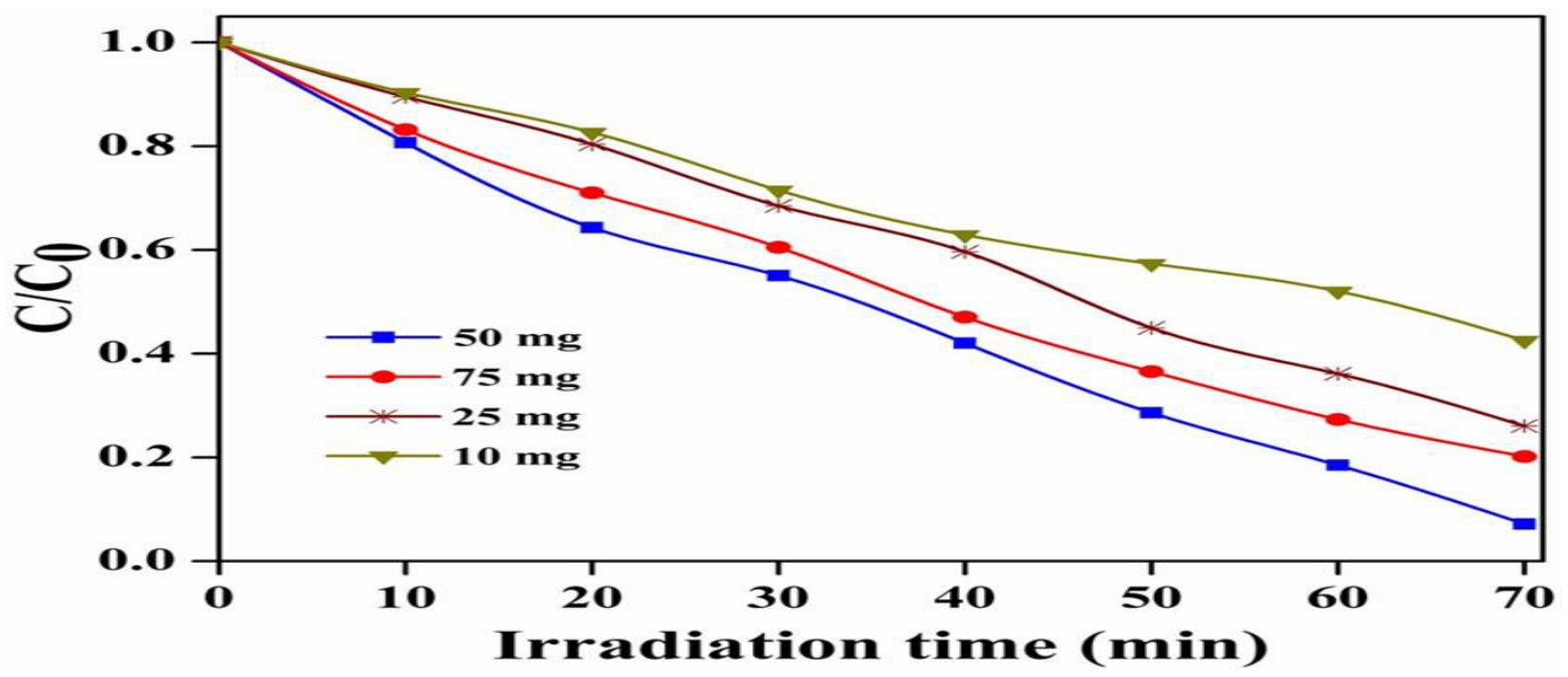

Fig.-9: Photodegradation of RhB with Different Catalyst Amount in the Presence of $\mathrm{WO}_{3}$ Photocatalyst

\section{Detection of Reactive Oxygen Species}

Photodegradation of dyes by the semiconductor is usually completed by photoexcited electrons and holes together. On the basis of that, a series of reactive species like hydroxyl radical, active holes and superoxide radicals generated. The effect of different scavengers on the photocatalytic degradation of dye solutions was investigated to find out the reactive oxidative species involved in the mechanism. The hydroxyl radical $(\bullet \mathrm{OH})$ scavenger, benzoic acid (BA) were used to detect the involvement of $\bullet \mathrm{OH}$ in the photocatalytic reaction. It was found that the degradation rate of $\mathrm{RhB}$ 
was suppressed upon the addition of BA which suggested the involvement of $\mathrm{OH}$. Triphenylphosphene (TPP), azide ion (AZ) and acrylamide (AA) are the singlet oxygen generator and superoxide radical anion $\left(\mathrm{O}_{2} \bullet-\right)$ quencher respectively, which enhanced the rate of photocatalytic reaction proceeds by the $\mathrm{O}_{2} \bullet-{ }^{26,27}$. In the present study, the rate of photodegradation was affected by a catalytic scavenger. BA shows the involvement of $\bullet \mathrm{OH}$ and TPP, AZ and AA shows the involvement of $\mathrm{O}_{2} \bullet$-in the degradation of $\mathrm{RhB}$ which is shown in Fig.-10. These results show that the photocatalytic degradation was preceded by the involvement of $\bullet \mathrm{OH}$ as well as $\mathrm{O}_{2} \bullet$.

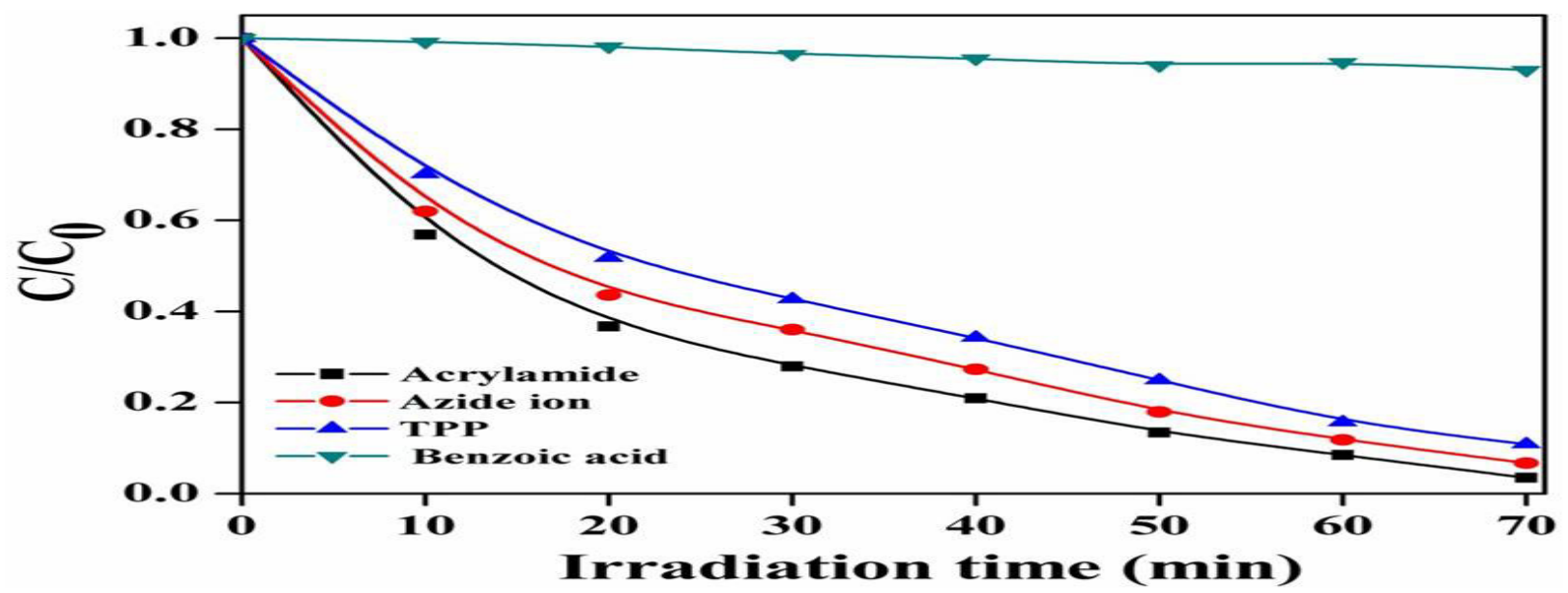

Fig.-10: Photodegradation of $\mathrm{RhB}$ with Different Scavengers in the Presence of $\mathrm{WO}_{3} \mathrm{Photocatalyst}$

\section{Photocatalytic Degradation Mechanism}

On the basis of the experimental results and from the literature, the photocatalytic degradation mechanism of $\mathrm{RhB}$ dye solution by the $\mathrm{WO}_{3}$ photocatalyst under visible light irradiation was proposed by Equations (3) to (8), as follows:

$$
\begin{gathered}
\mathrm{WO}_{3}+\mathrm{hv} \rightarrow \mathrm{WO}_{3}\left(\mathrm{~h}^{+}(\mathrm{wb})+\mathrm{e}^{-}(\mathrm{cb})\right. \\
\mathrm{WO}_{3}\left(\mathrm{e}^{-}(\mathrm{cb})\right)+\mathrm{O}_{2} \rightarrow \mathrm{WO}_{3}+\mathrm{O}_{2}^{-} \\
\mathrm{O}_{2}^{-}+\mathrm{H}^{+} \rightarrow . \mathrm{HO}_{2} \\
\mathrm{WO}_{3}\left(\mathrm{e}^{-}(\mathrm{cb})\right)+\mathrm{HO}_{2}+\mathrm{H}^{+} \rightarrow \mathrm{H}_{2} \mathrm{O}_{2} \\
\mathrm{H}_{2} \mathrm{O}_{2}+\mathrm{WO}_{3}\left(\mathrm{e}^{-}(\mathrm{cb})\right) \rightarrow . \mathrm{OH}+\mathrm{OH}^{-} \\
\mathrm{O}_{2}^{-} / \mathrm{OH}+\text { dye } \rightarrow \text { mineralized products }
\end{gathered}
$$

Upon irradiation of $\mathrm{WO}_{3}$ photocatalyst under visible light an electron $\left(\mathrm{e}_{\mathrm{cb}}-\right)$ in the $\mathrm{VB}$ was excited to the $\mathrm{CB}$, and a hole $\left(\mathrm{h}_{\mathrm{vb}}+\right.$ ) was generated in the VB simultaneously (Equation (3)). The electrons at the photocatalyst surface were inhibited by the ubiquitously present molecular oxygen to yield first the superoxide radical anion,. $\mathrm{O}_{2}$ (Equation (4)). The superoxide radical anion. $\mathrm{O}_{2}$ further combined with $\mathrm{H}$ to generate .HO (Equation (5)). The .OH radical can be formed from the trapped electron after formation of the. $\mathrm{HO}_{2}$ radical (Equations (7) and (8)). Lastly, the photocatalytic degradation of the dyes can take place through Equation (8). The active oxygen species (.OH, . $\mathrm{HO}_{2}$ or. $\mathrm{O}_{2}$ radicals) or the $\mathrm{h}_{\mathrm{vb}}+$ attacked the dyes, and the dyes were degraded gradually. For example, the basic dye adsorbs the proton and protonates and this protonation continues and the degraded products are obtained after the certain period of time.

\section{Stability of the Photocatalyst}

The stability of the synthesized photocatalyst was evaluated by the recycling test and the results are shown in Fig.-11. The photocatalyst showed radically stable even after its fifth cycle run. The 
results showed that the photocatalytic activity of the $\mathrm{WO}_{3}$ nanorods was decreased in the third cycle and subsequently maintained relative stability. The decreased percentage in degradation might be due to the adsorption of intermediate products on the active photocatalyst sites which rendered them unavailable for the photodegradation of the fresh dye solution.

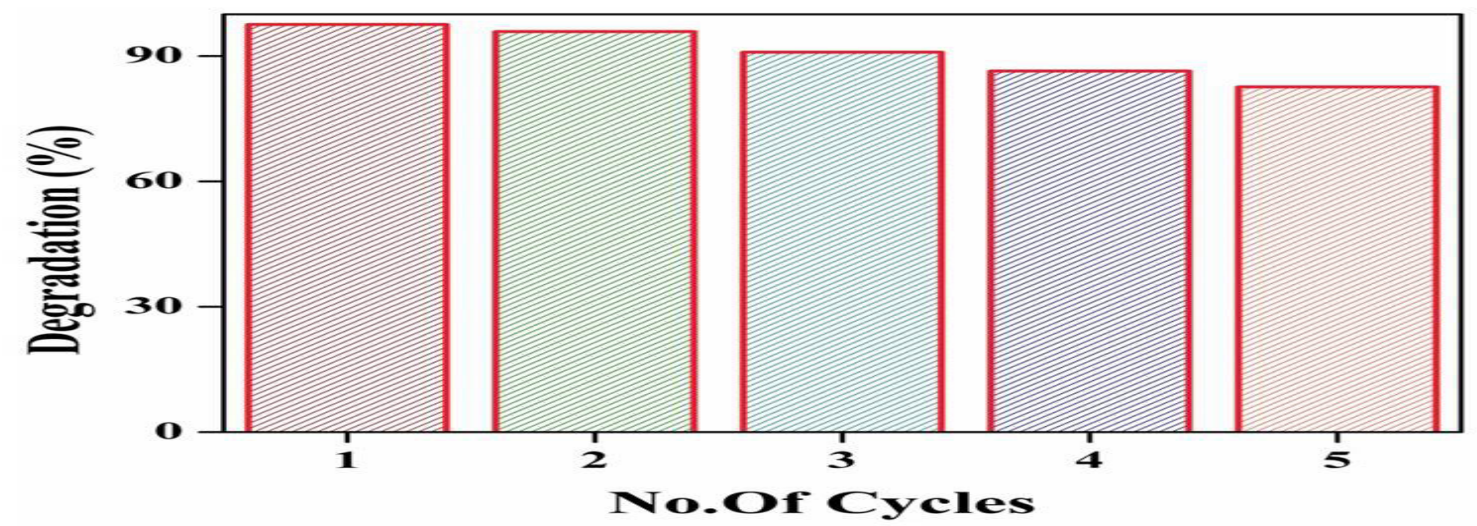

Fig.-11: Reusability of $\mathrm{WO}_{3}$ Photocatalyst as A Function of Percentage

\section{CONCLUSION}

Novel $\mathrm{WO}_{3}$ nanorods were prepared by simple and efficient hydrothermal method. The synthesized $\mathrm{WO}_{3}$ nanorods were analyzed in detail. The $\mathrm{WO}_{3}$ nanorods exhibited superior crystallinity and excellent photocatalytic activity. In addition, hydroxyl radical and superoxide radical ion were proved to be main reactive species in the photodegradation of dye RhB solution. Photocatalytic activity is very sensitive when particles are small, which is important in photocatalytic degradation and lowering the number of charge carrier recombination. The photocatalyst also displayed good stability during photodegradation and its capability to be used in several experimental cycles. The present results show that $\mathrm{WO}_{3}$ nanorods are a promising material with high reactivity and stability for the photodegradation of dye solution under visible light irradiation.

\section{REFERENCES}

1. Z.L.Wang and W.Z. Wu, Angew. Chem., 5111700 (2012).

2. H. Tong, S.X. Ouyang, Y.P. Bi, N. Umezawa, M. Oshikiri, and J.H. Ye, Adv. Mater., 24229 (2011), DOI: $10.1002 /$ adma.201102752

3. M.R. Hoffmann, S.T. Martin, W. Choi, and D.W. Bahnemann, Chem. Rev., 95(1), 69(1995), DOI:10.1021/cr00033a004

4. A.W. Xu, W.Y. Gao, and H.Q. Liu, J. Catal., 207, 151(2002), DOI:10.1006/jcat.2002.3539

5. R. Nagarjuna, S. Challagulla, P. Sahu, S. Roy, R. Ganesan, Adv. Powder. Technol., 28, 3265 (2017), DOI: 10.1016/j.apt.2017.09.030

6. M. Kudo and Y. Miseki, Chem. Soc. Rev., 38, 253(2009), DOI:10.1039/B800489G

7. S. Tokunaga, H. Kato, and A. Kudo, Chem. Mater., 13, 4624 (2001), DOI:10.1021/cm0103390

8. S. Zhang, J. Li, X. Wang, Y. Huang, M. Zeng, J. Xu, ACS Appl. Mater. Interfaces, 6, 22116 (2014), DOI:10.1021/am505528c

9. S. Adhikari, D. Sarkar, H.S. Maiti, Mater. Res. Bull., 49, 325(2014), DOI: 10.1016/j.materresbull.2013.08.028

10. R. Karthik, J.V. Kumar, S. M. Chen, T. Kokulnathan, H. Yang, V. Muthuraj, ACS. Sustain. Chem. Eng., 6,8615, 2018, DOI: 10.1021/acssuschemeng.8b0093

11. J.V. Kumar, R. Karthik, S. M. Chen, N. Karikalan, K. Chelladurai, C. C. Yang, V. Muthuraj, Nano. Micro. Lettl., 10, 15652 (2018), DOI: 10.1021/acsami.8b00625.

12. J. V. Kumar, R.Karthik, S. M. Chen, V. Muthuraj, K. Chelladurai, Sci. Rep., 6, 34149 (2016), DOI:10.1038/srep34149. 
13. J. V. Kumar, R. Karthik, S. M. Chen, K. H. Chen, S. Sakthinathan, V. Muthuraj, T. W. Chiu, Chem. Eng. J., 346, 11(2018), DOI:10.1016/j.cej.2018.03.183

14. R. Karthik, J. V. Kumar, S. M. Chen, K. Chelladurai, V. Muthuraj, ACS Appl. Mater. Interfaces, 9 , 6547(2017), DOI: 10.1021/acsami.6b14242.

15. T. Peng, D. Ke, J. Xiao, L. Wang, J. Hu, L. Zan, J. Solid State Chem., 194, 250(2012), DOI:10.1016/j.jssc.2012.05.016.7

16. Z. Jiao, J. Wang, L. Ke, X. W. Sun, H. V. Demir, ACS Appl. Mater. Interfaces, 3, 229(2011), DOI: $10.1021 / a m 100875 z$

17. Y. Zhang, Y. Chen, H. Liu, Y. Zhou, R. Li, M. Cai, X. Sun, J. Phy. Chem. C, 113 1746(2009), DOI: $10.1021 / \mathrm{jp} 808774 \mathrm{~m}$

18. A. M. Cruz, D. S. Martinez, E. L. Cuellar, Solid State Sci., 12,88(2010), DOI:10.1016/j.solidstatesciences.2009.10.010

19. W. Yu, J. Chen, T. Shang, L. Chen, L. Gu, T. Peng, Appl. Catal. B, 219, 693(2017), DOI:10.1016/j.apcatb.2017.08.018.

20. K. Prakash, P. S. Kumar, S. Pandiaraj, K. Saravanakumar, S. Karuthapandian, J. Exp. Nanosci., 11, 1138(2016), DOI:10.1080/17458080.2016.1188222

21. A. B. Murphy, Sol. Energy Mater. Sol. Cells, 91, 1326 (2007), DOI:10.1016/j.solmat.2007.05.005

22. M.E. Khan, M.M. Khan, M.H. Cho, RSC Adv., 6, 20824 (2016), DOI:10.1039/C5RA24575C

23. L. Zhang, Y. Li, Q. Zhang, H. Wang, Cryst. Eng. Comm., 15, 5986(2013), DOI:10.1039/C3CE40620B

24. K .Prakash, P. S. Kumar, P. Latha, K. S. Durai, R. Shanmugam, S. Karuthapandian, Mater. Res. Bull., 93, 112 (2017), DOI:10.1016/j.materresbull.2017.04.018

25. P.S. Kumar, M. Selvakumar, S.G. Babu, S. Karuthapandian, Mater. Res. Bull., 83, 522(2016), DOI:10.1016/j.materresbull.2016.06.043

26. K. Prakash, P. S. Kumar, P. Latha, K. Saravanakumar, S. Karuthapandian, J. Inorg. Organomet. Polym., 28, 268 (2018), DOI:10.1007/s10904-017-0715-5

27. P.S. Kumar, M. Selvakumar, S.G. Babu, S. Induja, S. Karuthapandian, J. Alloy. Compd., 701, 562 (2017), DOI:10.1016/j.jallcom.2017.01.126.

, [RJC-3076/2018] 